\title{
Acute abdomen and hemorrhagic shock caused by spontaneous rupture of renal cyst in autosomal dominant polycystic kidney disease
}

İsmail Yaman', İsmet Sağlam², Kamile Kurt ${ }^{3}$

ABSTRACT

'Department of General Surgery, Balıkesir University Faculty of Medicine, Ballkesir, Turkey

${ }^{2} \mathrm{Clinic}$ of General Surgery, Manisa Merkez Efendi State Hospital, Manisa, Turkey

${ }^{3}$ Clinic of Pathology, Manisa Merkez Efendi State Hospital, Manisa, Turkey

\section{Address for Correspondence Dr. İsmail Yaman Department of General Surgery, Balıkesir University Faculty of Medicine, Balıkesir, Turkey Phone.: +90266245 4425 e-mail: ismailyaman35@gmail.com}

Received: 28.08.2011

Accepted: 18.11.2011

@Copyright 2013 by Turkish Surgical Association

Available online at www.ulusalcerrahidergisi.org
Autosomal dominant polycystic kidney disease is an important cause of end stage renal failure. Rarely, these patients may present with hemorrhagic shock caused by rupture of the renal cyst. The aim of this study was to report a rare case of a patient who arrived at the emergency department with autosomal dominant polycystic kidney disease presenting with acute abdominal pain and hemorrhagic shock. A 58-year-old male with chronic renal failure was admitted to the emergency department with acute abdominal pain and hemorrhagic shock. The patient was admitted to the Department of Surgery with diagnosis of acute abdomen and perirenal hematoma. Although the patient was on conservative treatment, his symptoms did not improve and the patient was operated emergently. During exploration, there was bleeding from the right polycystic kidney, which was $30 \times 20 \mathrm{~cm}$ in dimension. The patient underwent nephrectomy and drainage of the hematoma, and was discharged on the fifth postoperative day without any problems. Bleeding due to rupture of a cyst in autosomal dominant polycystic kidney disease occurs rarely but it may be life threatening. Although conservative methods are often preferable in treatment, surgery can be life saving for patients in whom the clinical situation does not improve.

Key Words: Autosomal dominant disease, polycystic kidney disease, retroperitoneal hematoma, hemorrhagic shock, acute abdomen

\section{INTRODUCTION}

Autosomal dominant polycystic kidney disease (ADPKD) is a systemic disease associated with various renal and non-renal manifestations and is one of the most important reasons of end stage renal failure (1-3). The disease usually presents in the $4^{\text {th }}$ and $5^{\text {th }}$ decades $(1,4)$. The most common symptoms are flank pain and hematuria, while life-threatening complications such as bleeding may rarely develop $(1,5,6)$.

In patients with autosomal dominant polycystic kidney disease, while hemorrhage within the cysts is frequently seen, hematoma surrounding the kidney is a rare (3\%) and a dramatic complication (5-8). In patients with renal hematoma, depending on the degree and duration of bleeding hemorrhagic shock may rarely develop $(3,7,9)$. Computed tomography (CT) and magnetic resonance imaging are the best diagnostic tools $(6,7)$. Treatment is usually conservative, invasive procedures such as renal artery embolization or nephrectomy is required only in complicated cases $(6,8)$.

In this study, we aimed to report on a rare case who presented to our clinics with renal hematoma following spontaneous cyst rupture and hemorrhagic shock in a patient with ADPKD.

\section{CASE PRESENTATION}

A 58-year-old male patient presented to the emergency department with complaints of sudden onset abdominal pain that began 6 hours ago, nausea, vomiting, weakness, and dizziness. His past medical history revealed agenesis of the left kidney, and that he was undergoing hemodialysis for the last 12 years due to chronic renal failure caused by ADPKD. On physical examination, the patient was cachectic in appearance, and the abdomen was distended. His skin was pale, cold and moist with an arterial blood pressure of $70 / 50 \mathrm{mmHg}$, and a pulse rate of $150 / \mathrm{min}$. On palpation an umbilical hernia and an immobile, irregular bordered mass was found that filled the right hypocondrium, lumbar and inguinal regions. Rebound tenderness and guarding was present in all quadrants, being most prominent in the right hypocondrium. The bladder was catheterized, an $10 \mathrm{cc}$ of urine was drained.

The results of complete blood count, biochemistry and blood gas tests were within normal range except Hgb: $7.2 \mathrm{~g} / \mathrm{dL}$, Hematocrit: $21.9 \%$, WBC: $12.06 \times 10^{3} \mathrm{~K} / \mathrm{mm}^{3}, \mathrm{MCV}: 99.8 \mathrm{fL}$, Urea: $136 \mathrm{mg} / \mathrm{dL}$, Creatinine: $8.8 \mathrm{mg} / \mathrm{dL}$, Potassium: $5.6 \mathrm{mmol} / \mathrm{L}$. The plain abdominal x-ray showed an air-fluid level in the left upper quadrant. The abdomen ultrasonography revealed the left kidney cannot be visualized, a $50 \times 40 \mathrm{~cm}$ mass (suspicious for hematoma) which filled the entire right retroperitoneal area, within the mass the 
kidney was seen as $30 \times 20 \mathrm{~cm}$ in size containing multiple cysts together with cholelithiasis. Abdominal CT showed diffuse hematoma in the right retroperitoneum and active bleeding in the perinephritic area.

The patient was hospitalized with a diagnosis of acute abdomen -perirenal hematoma. The central venous pressure (CVP) was measured as $-2 \mathrm{~cm} \mathrm{H}_{2} \mathrm{O}$. Three units of packed red blood cells transfusions and fluid replacement was given, the blood pressure was still $90 / 60 \mathrm{mmHg}$, and the CVP $+1 \mathrm{~cm} \mathrm{H}_{2} \mathrm{O}$, the abdominal symptoms did not subside during follow-up. Internal medicine was consulted and it was stated that the patient did not require an emergency dialysis. It was then decided to perform an emergent operation.

On abdominal exploration, a giant retroperitoneal hematoma of $50 \times 40 \mathrm{~cm}$ in size that extended from the inferior of the liver to the pelvis, covering the right retroperitoneum completely, reaching to the transverse mesocolon and gallbladder was detected. The right kidney was polycystic and had a hemorrhagic and necrotic appearance with a size of $30 \times 20 \mathrm{~cm}$. The left kidney could not be palpated. The patient underwent retroperitoneal hematoma drainage, right nephrectomy, cholecystectomy, and umbilical hernia repair. In the macroscopic examination a nephrectomy specimen of $29 \times 21 \times 12 \mathrm{~cm}$ dimensions, containing numerous cyst, the largest being $6 \mathrm{~cm}$. in size, filled with serosanguinous material, with areas of bleeding and necrosis was found (Figure 1, 2). On microscopic examination, benignappearing cysts lined with single-layered epithelium, a view of thyroidisation and increase in fibrous tissue with inflammatory cell infiltration were present. The patient underwent hemodialysis in the postoperative period, and was discharged on the fifth day without any problems.

\section{DISCUSSION}

Autosomal dominant polycystic kidney disease is the most common hereditary renal disease and is a major cause of end stage renal failure $(2,10)$. In Europe and America, approximately $10 \%$ of chronic dialysis patients have $\operatorname{ADPKD}(2,4)$. As part of this disease, regarding the kidneys; asymptomatic proteinuria, chronic pain, hypertension, hematuria, cyst infection, rupture, renal failure, renal tumor can be seen together with non-renal pathologies such as liver cysts, intracranial aneurysms, heart valve abnormalities, diverticula and hernias $(1,3,4)$. The dis-

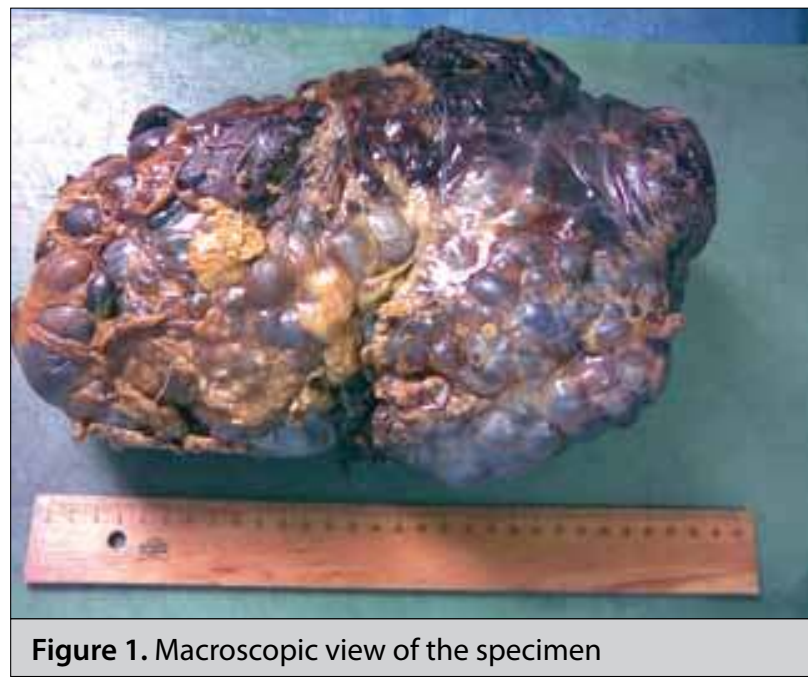

ease usually manifest in the $4^{\text {th }}$ and the $5^{\text {th }}$ decades (4). Our patient was 58 years old, and was undergoing hemodialysis for 12 years for chronic renal failure. In our patient, non-renal involvement except umbilical hernia was not detected.

While bleeding into the cysts is frequent, rupture of the cyst is rare $(5,9)$. Cyst rupture may develop either secondary to trauma or infections or may be spontaneous (9). Our patient had no history of trauma, he had a spontaneous cysts rupture that caused hemorrhagic shock.

Cyst rupture is reported to present with different clinical pictures depending on the degree and severity of bleeding, ranging from chest pain and hematuria to hemorrhagic shock (6 , 7). The treatment is usually by conservative methods including bed rest, blood transfusion and analgesic treatment $(6,8)$. Surgical intervention is reserved for patients in whom hemodynamic instability and acute abdominal findings persist despite conservative methods such as bed rest and blood transfusion $(6,8,11)$.

In recent years, with advances in interventional radiology and $\mathrm{CT}$ technology in reference centers, conservative treatment with angiography and arterial embolization is recommended (8). The majority of patients respond well to conservative treatment $(8,9)$. In our patient, sudden onset of acute abdomen and signs of hemorrhagic shock was present. The patient was started on medical therapy. Detection of active bleeding in $\mathrm{CT}$, continued hemodynamic instability, persistence of acute abdominal findings despite analgesic therapy were accepted as indications for emergent surgery. Hematoma drainage and right nephrectomy was performed. He was discharged on the fifth postoperative day without any complications.

\section{CONCLUSION}

Hemorrhage due to cyst rupture in autosomal dominant polycystic kidney disease is a rare but life-threatening condition. Although conservative treatment methods are preferred, surgery can be lifesaving in patients without clinical improvement.

Peer-review: Externally peer-reviewed.

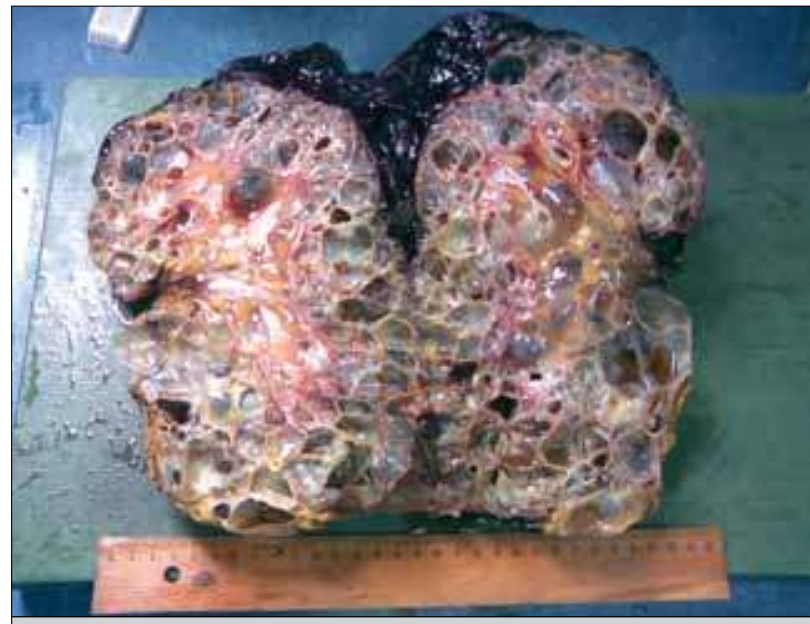

Figure 2. Macroscopic view of a section of the specimen 
Author Contributions: Study concept and design - I.Y.; Acquisition of data - I.Y., I.S., K.K.; Analysis and interpretation of data - I.Y., I.S., K.K.; Preparation of the manuscript - I.Y.

Conflict of Interest: No conflict of interest was declared by the authors.

Financial Disclosure: The authors declared that this study has received no financial support.

\section{REFERENCES}

1. Fick GM, Johnson AM, Hammond WS, Gabow PA. Causes of death in autosomal dominant polycystic kidney disease. J Am Soc Nephrol 1995; 5: 2048-56.

2. Chijioke A, Aderibigbe A, Olarenwaju TO, Makusidi AM, Oguntoyinbo AE. Prevalence and pattern of cystic kidney diseases in llorin, Nigeria. Saudi J Kidney Dis Transpl 2010; 21: 1172-8.

3. Bajwa ZH, Gupta S, Warfield CA, Steinman TI. Pain management in polycystic kidney disease. Kidney Int 2001; 60: 1631-44. [CrossRef]

4. Şen S. Uro-oncology and cystic lesions of the kidney. Üroonkoloji Bülteni 2007; 1: 7-16.

5. Bagon JA. Hemoperitoneum originating in renal cyst in a patient with ADPKD not treated by dialysis. Nephrol Dial Transplant 2000; 15: 251-3. [CrossRef]
6. Sirvent $A E$, Enríquez R, Cabezuelo JB, Ortí C, Amorós F, Reyes A. Autosomal dominant polycystic kidney disease presenting with prolonged macrohaematuria and perinephric haematoma. Nephrol Dial Transplant 1998; 13: 2422-3. [CrossRef]

7. Reiter WJ, Haitel A, Heinz-Peer G, Pycha A, Marberger M. Spontaneous nontraumatic rupture of a contracted kidney with subcapsular and perirenal hematoma in a patient receiving chronic hemodialysis. Urology 1997; 50: 781-3. [CrossRef]

8. Nishikawa Z, Kataoka A, Yuasa T, Okamoto K, Wakabayashi Y, Yoshiki $T$, et al. [Renal cell carcinoma in acquired cystic disease of the kidney manifested by spontaneous renal hemorrhage]. Nihon Hinyokika Gakkai Zasshi 2000; 91: 727-30.

9. Tarrass $F$, Benjelloun M. Acute abdomen caused by spontaneous renal cyst rupture in an ADPKD haemodialysed patient. Nephrology 2008; 13: 177-80. [CrossRef]

10. Altıparmak MR, Seyahi N. Advances in renoprotection in autosomal dominant polycystic kidney disease. Turkiye Klinikleri, J Int Med Sci 2005; 1: 40-3.

11. Ishikawa $E$, Kudo, $M$, Minami $Y$, Ueshima $K$, Chung $H$, Hayaishi $S$, et al. Intracystic hemorrhage in a patient of polycystic kidney with renocolic fistula diagnosed by contrast-enhanced ultrasonography. Inter Med 2008; 47: 1977-9. [CrossRef] 